Document downloaded from:

http://hdl.handle.net/10251/97086

This paper must be cited as:

Pastor, JV.; Serrano, J.; Dolz, V.; López Hidalgo, M.; Bouffaud, F. (2012). Study of turbocharger shaft motion by means of non-invasive optical techniques: Application to the behaviour analysis in turbocharger lubrication failures. Mechanical Systems and Signal Processing. 32:292-305. doi:10.1016/j.ymssp.2012.04.020

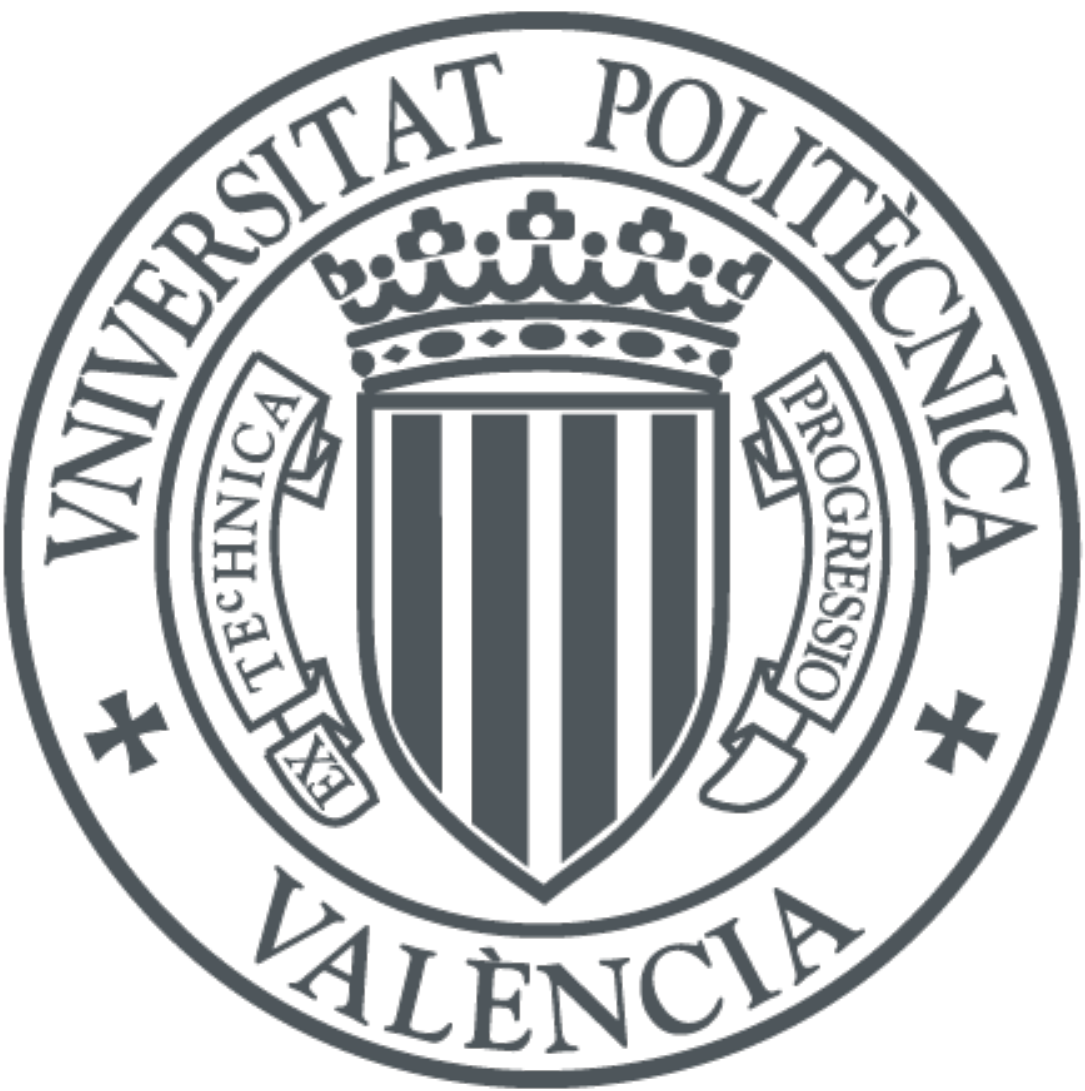

The final publication is available at

http://doi.org/10.1016/j.ymssp.2012.04.020

Copyright ACADEMIC PRESS LTD- ELSEVIER SCIENCE LTD

Additional Information 


\title{
Study of turbocharger shaft motion by means of non-invasive optical techniques. Application to the behaviour analysis in turbocharger lubrication failures
}

\author{
JV Pastor $^{\text {a }}$, JR Serrano ${ }^{\text {a }}$, V Dolz $^{\text {a, * }}$, MA López ${ }^{\text {a }}$, F Bouffaud ${ }^{\text {b }}$ \\ ${ }^{a}$ CMT - Motores Térmicos, Universitat Politècnica de València, Spain \\ ${ }^{\mathrm{b}} \mathrm{RSA}$ - Renault SA, France
}

\begin{abstract}
This paper presents a novel non-invasive technique to estimate the turbocharger shaft whirl motion. The aim of this article is to present a system for monitoring the shaft motion of a turbocharger, which will be used in turbocharger destructive testing. To achieve this, a camera and a light source were installed in a turbocharger test bench with a controlled lubrication circuit.

An image recording methodology and a process algorithm have been developed, in order to estimate the shaft motion. This processing consists on differentiating specific zones of the image, in order to obtain their coordinates. Two reference points have been configured on the compressor side, which help to calculate the relative position of the shaft, avoiding the errors due to structural vibrations. Maximum eccentricity of the turbocharger has been determined and it has been compared with shaft motion when it is spinning in different conditions. A luminosity study has been also done, in order to improve the process and to obtain locus of shaft position in a picture exposition time period.

The technique has been applied to diagnosis of a lubrication failure test and the main results will be presented in this article: like shaft motion figures; thermodynamic variables and pictures of the shaft while it is spinning at abnormal lubrication conditions. The measuring components used in this technique have the ability to withstand the catastrophic failure of the turbocharger in this type of test.
\end{abstract}

Keywords: Turbocharger, Lubrication, Bearing, Shaft motion.

\footnotetext{
* Corresponding author. Tel.: +34 963877650; Fax: +34 963877659.

Camino de Vera s/n, 46022 Valencia, Spain

E-mail address: vidolrui@mot.upv.es (V. Dolz).
} 


\section{INTRODUCTION}

Nowadays, the tendency to reduce the cylinder capacity -downsizing- in reciprocating internal combustion (IC) engines requires the use of turbochargers. The final objective of this boost is to maintain or increase the engine air mass flow, thereby increasing engine power. The performance and reliability of these turbochargers is related with many factors like mechanical losses, heat transfer, shaft motion, lubrication, etc.

The dynamic model of the shaft has been studied extensively since the early twentieth century until nowadays [1] [2] [3] [4]. The focus of these models has changed with technological developments, from the purely theoretical until their validation by experimental techniques. These types of models have been used to study the operative problems of turbomachinery [5]. Nowadays, some experimental measurement techniques with accelerometers [6] and laser [7], feedback these models, and both models and experimental techniques contribute to improve the knowledge about the functioning of these shafts.

The lubrication problems in these turbochargers have been extensively studied both experimentally, by measuring the thermodynamic variables in turbocharger test benches [8], and theoretical, by means of CFD models [9] [10]. In this paper the whirl movement of the shaft of an IC engine turbocharger is measured by digital processing of high magnification images of the rotor axis during normal and abnormal operation. The objective is to obtain information about the whirl shaft movement previous to and during turbocharger lubrication failure tests. This information goes from the movement of the shaft to another type of visual information, as the apparition of oil on the compressor side, or the deformation of the shaft tip. Furthermore, this technique is not intrusive and robust enough to avoid the destruction of the measurement components if a catastrophic failure of the turbocharger happens. To accomplish these objectives, a window in the compressor inlet duct with a camera focused on the shaft tip has been used [11]. To obtain the expected results some difficulties presented by the test bench Diesel engines used in turbocharging [12] [13] should be considered such as structural vibration and space to install the equipment. During these tests, turbocharger thermodynamic variables have been also recorded to obtain complete information on the evolution of the turbocharger when it has lubrication problems [14].

This paper describes the test bench configuration and the different image processing techniques to obtain information about the shaft motion.

\section{TEST BENCH LAYOUT}

The turbine feeding gas is provided by a 6 cylinders heavy duty diesel engine (Table 1). More details about test bench components and configuration can be found in reference [11]. The flow intake is controlled by means of a guillotine valve, allowing accelerating, decelerating and fixing the working point of the turbocharger. A 3-way valve controls 
the lubrication oil circuit and it allows the turbo lubrication or cutting the oil flow to the turbo. Additionally, transducers were emplaced in the oil circuit, turbine gas circuit and compressor air circuit to measure thermodynamic variables, such as pressure, temperature and mass flow (Figure 1).

\begin{tabular}{|lc|}
\hline Number of cylinders & 6 \\
Piston Bore & $150 \mathrm{~mm}$ \\
Stroke & $125 \mathrm{~mm}$ \\
Compression ratio & $17: 1$ \\
Max. speed & $1800 \mathrm{rpm}$ \\
\hline
\end{tabular}

Table 1. Characteristics of the engine used in the turbocharger test bench

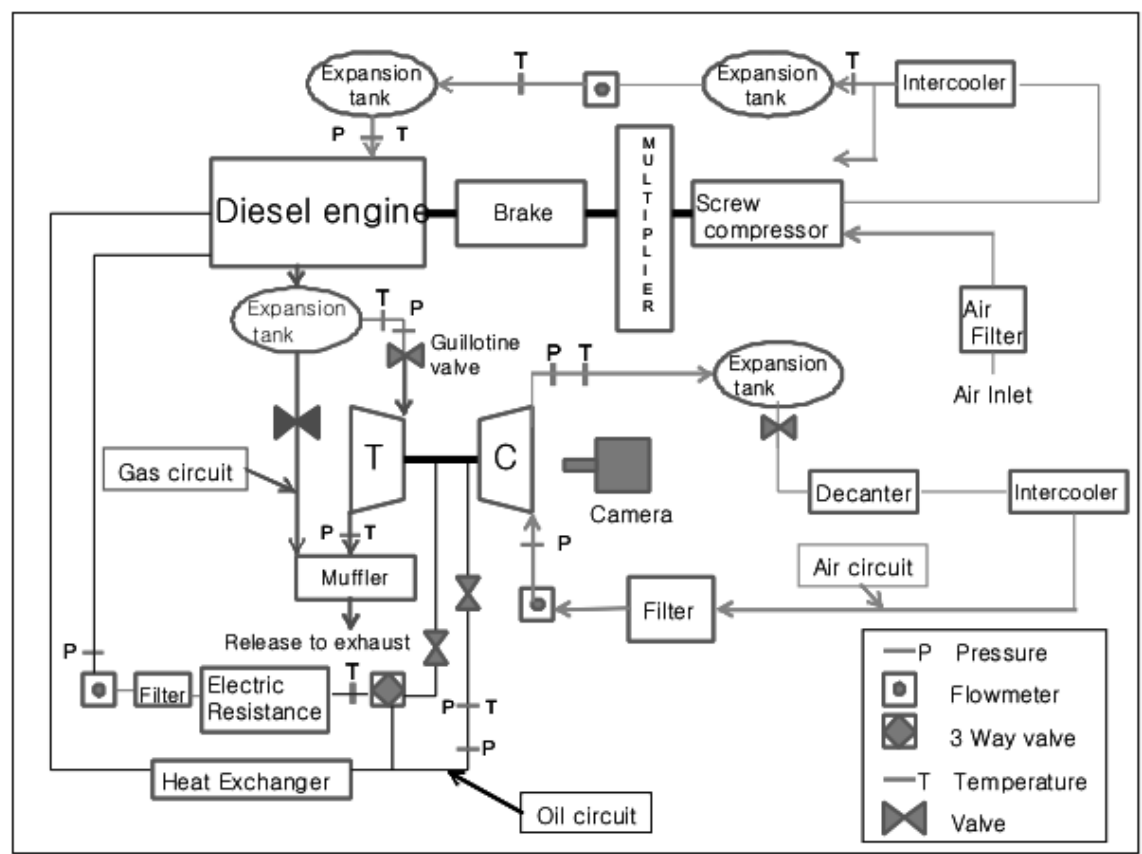

Figure 1 General sketch of the Test Bench

The camera is placed in front of the turbocharger on the compressor side, positioning it as coaxial as possible to the turbocharger shaft and focused to the shaft tip. A $90^{\circ}$ elbow is attached at the inlet of the compressor housing with a glass window to allow the proper display of the shaft through the camera (Figure 2). Light provided by a $250 \mathrm{~W}$ halogen lamp is driven to the test section through two liquid light guides, which have 8 $\mathrm{mm}$ in diameter. These probes are arranged in a horizontal plane and are coupled into the duct, pointing to the tip of the compressor shaft (Figure 2). The function of these probes is properly enlighten the shaft to get photographs with enough quality for further processing. 


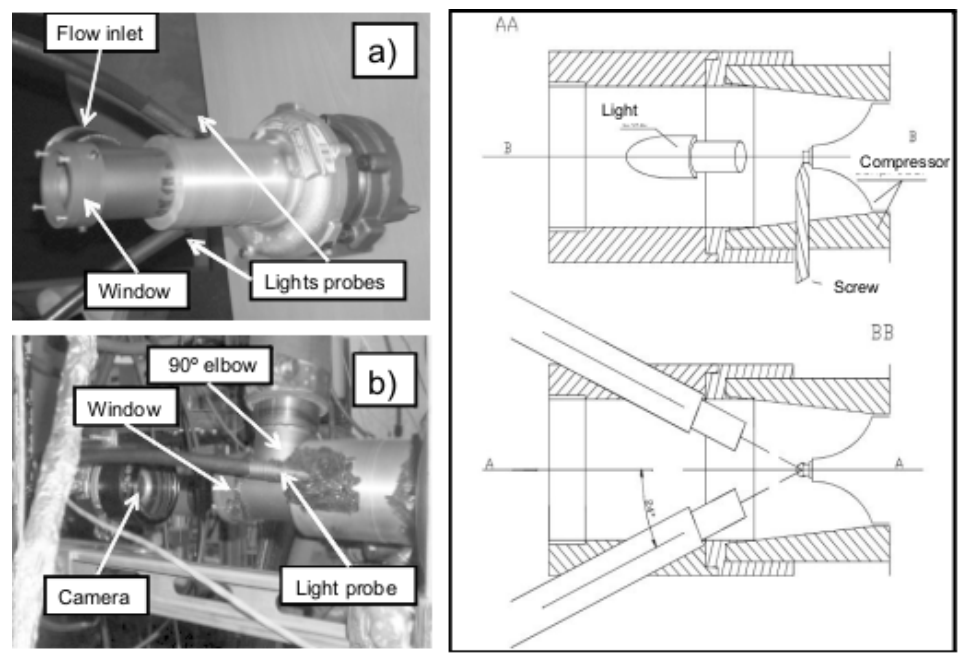

Figure 2. Camera layout and lights probes sketch

Images are taken with a PCO Pixelfly 12-bit CCD Camera with spatial resolution of $1280 \times 1024$ pixels. The distance between the compressor and the camera is approximately $300 \mathrm{~mm}$.

The resolution obtained with this layout is approximately $5 \mu \mathrm{m}$ per pixel. This resolution allows us to observe the shaft movements, which have similar order of magnitude.

A major problem of this measurement technique is the relative motion between the camera and the turbocharger while the shaft motion is being measured. Structural vibrations in the reciprocating engines or in the turbocharger test benches are quite common and they introduce uncontrolled displacement between camera and turbo, which can introduce a significant error the in measurements. To avoid this, two screws, whose tips are located a few millimetres from the compressor shaft tip, are placed in the compressor housing. These screws are used to facilitate the processing of the images, offering two clear references fixed with the turbo housing. The previously stated error sources can be avoided using these fixed references.

It is necessary to distinguish clearly the objects in the image, in order to find the shaft position through the recorded pictures. So, the screws have been painted white and the compressor wheel has been painted black, leaving the shaft tip shining. These colors are used in order to improve the image processing. This processing involves identifying the position of the important objects (screws and shaft tip) and distinguishing luminosity of the pixels in the image (this technique is explained in the next paragraphs). Figure 3 shows the compressor side of the turbocharger with the focused camera frame and the 2 reference screws. 


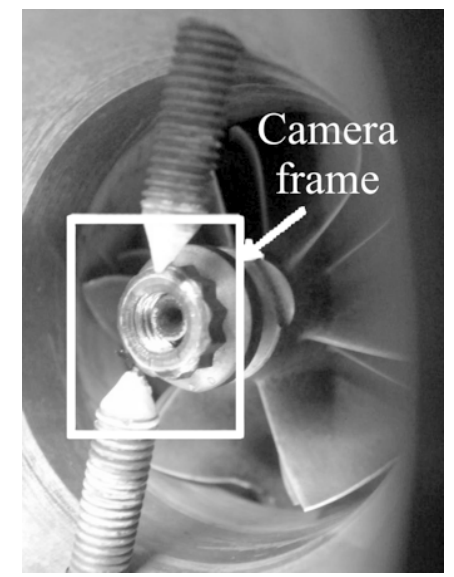

Figure 3 Photograph of screws and tip shaft

The turbochargers shaft tips have several shapes; they depend on the compressor nut configuration. Two kinds of turbochargers have been used for this work, the first one is a Borg Warner turbocharger (BWTS) (with the shape of the shaft tip like a circle) and the second one is a Honeywell turbocharger (HTT) (with the shape of the shaft tip like a ring). An example of captured images by the camera with stopped shaft and rotating shaft can be observed in Figure 4. As the exposure time of the photograph has the same order of magnitude as the time per revolution of the turbocharger shaft, the image obtained from the rotating shaft has a smoother contour than the stationary shaft. This has implications for the accuracy of the method and the image processing, as it will be described in the following sections.
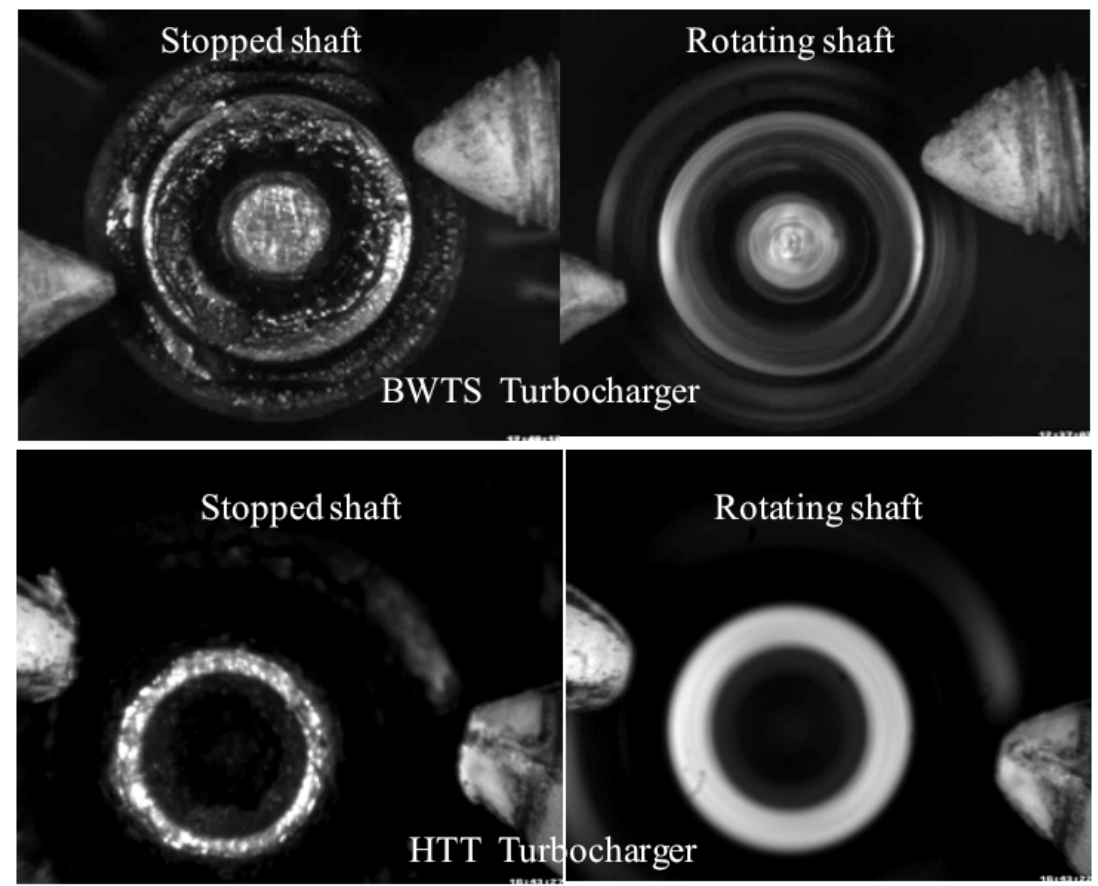

Figure 4 Photographs of the compressor shaft tip 
Different image processing codes have been programmed in Matlab, in order to obtain the relative position of the shaft centre from the photographs.

The shaft motion analysis process consists of four steps that are detailed below. The first step includes as well: the positioning of reference points (reference screws) and shaft centre in the picture, the determination of the scales in mm per pixel and the correction of the absence of perpendicularity between the camera and the turbocharger housing. The second step is to determine maximum eccentricity of the shaft in the turbocharger before the test. The third step is to determine the position of the shaft when it is spinning and its position relative to the maximum eccentricity determined in the previous step. The forth step is the analysis of shaft luminosity to determine if sudden movements have been done during the exposure time of the camera.

\subsection{Reference points and shaft position calculation}

The shape of the compressor shaft tip is considered a perfect circle or a perfect ring in the used code (Matlab). To improve the precision of the method, it has been assumed that the camera could not be located coaxially to the turbocharger shaft. Thus, this circle or ring has become an ellipse in the image process in order to consider the error due to the lack of coaxiality between camera and shaft tip.

As mentioned above reference screws are used to avoid errors in processing images from structural vibrations. A set of pictures is recorded from a given experiment at which the shaft motion wishes to be known. The steps to estimate the positions of the reference points (screws) and the centre of the shaft in these pictures are following depicted:

a. The processing of the pictures. The pictures obtained are processed into a binary image with black and white pixels. An example of a photograph before and after processing can be seen in the figure below.

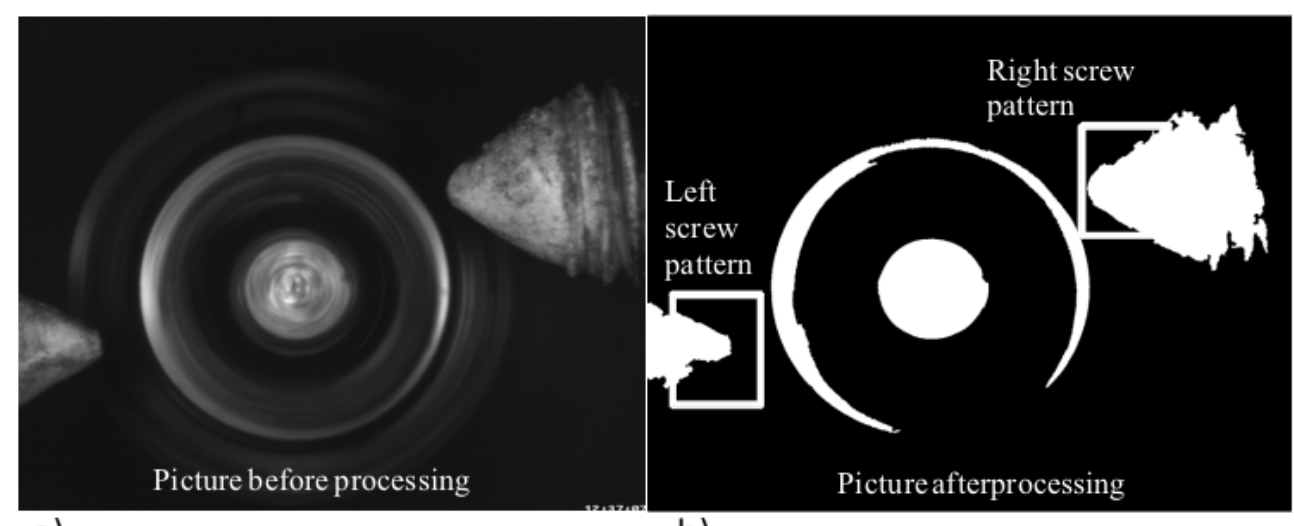

a)

b)

Figure 5 Pictures before (a) and after (b) processing 
b. Obtaining the screws patterns. The picture with the best quality (this is the photo whose brightness and focus have the highest quality) is chosen to be used as a standard for the reference screws. This photo is processed as in previous step and a binary image is obtained. The pictures of screws tips in these binary images are cut to use them as a pattern in the process of locating the screws in other photographs. Figure 6 a) shows an example of these patterns.

c. Reference point position. The program code used to determine the reference benchmarks compares these screws patterns with each one of the processed images in binary (black and white) format. This comparison is made in a range of coordinates where the program searches for the closest match between the shape of the processed image and the screw pattern. This convolution is performed by comparing the pixels of the two binary images using the logical operator "exclusive or" (XOR), seeking to minimize the number of pixels different between the two images. This range is represented with the large rectangle in Figure $6 \mathrm{~b}$ ). The figure also shows the left screw pattern in gray colour, at the point where the maximum coincidence has been found between the screw pattern and the processed image. The program establishes the centre of coordinates $(0,0)$ in the upper left position of the image, as Figure 8 shows. When the code of the program has found the best match between the reference screw and the screw of the image, it sets the coordinate of the pixel at the tip of the left screw (xi_ref, yi_ref) as a reference pixel. The process to find the position of the right screw (xd_ref, yd_ref) is similar to the process described previously for the left screw.

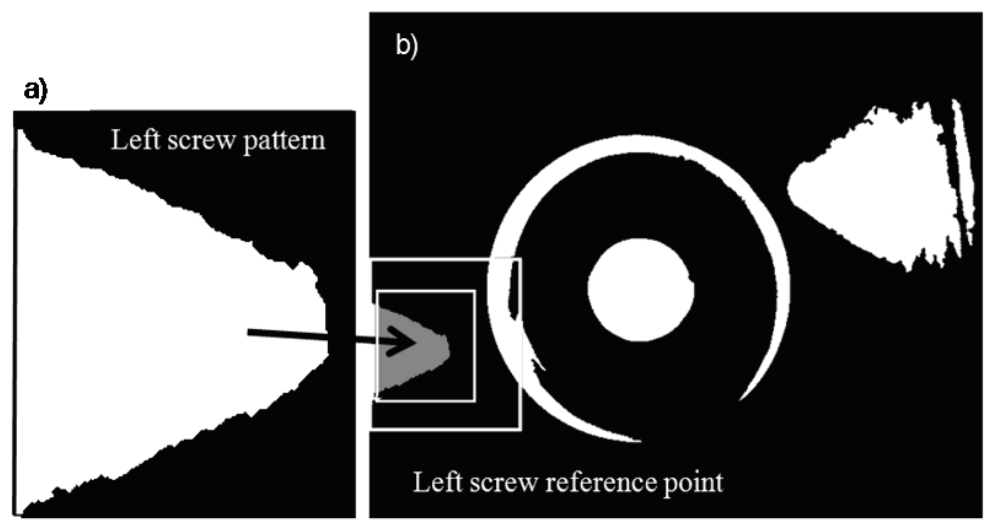

Figure 6 Position of the left screw reference point

d. Shaft tip centre position. The code programmed in Matlab searches a white circular shape which is at the centre of the processed image. Once the program finds this region, continues around the edge of this zone with white pixels, in order to complete the circular shape. This circular shape can be seen in Figure 7 with gray pixels. Using these gray pixel coordinates, the program approximates an ellipse and calculates its centre, its main angle and its semi-axes. The centre of this ellipse is shown in the Figure 7 by a small black dot. Then, the program 
sets the coordinate of the pixel at the ellipse centre (Xc, Yc) as the reference centre pixel, as Figure 8 shows.

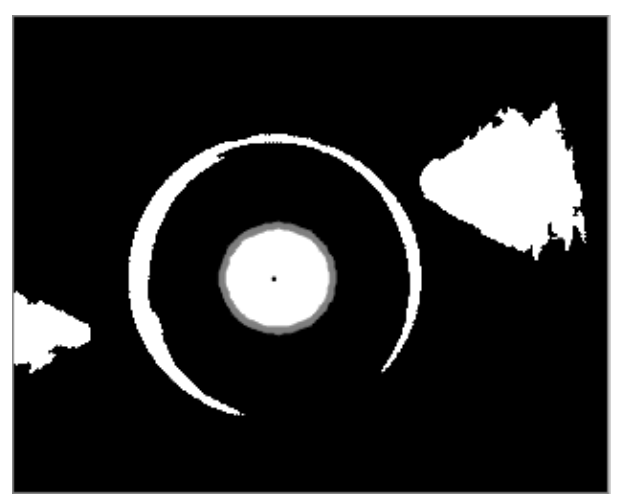

Figure 7. Position of the shaft tip centre

e. Coordinates and scales. A pre-processing methodology, previous to processing the results from the experiments with the shaft in motion, is done, in order to determine the scales of the images. In this pre-processing phase, it is necessary to take pictures from the turbocharger stopped. This pre-process involves a study of the shaft tip position and shape, to estimate the scales using these images where the shaft is stopped. It is possible to obtain the distances in pixels $\Delta \mathrm{x} \_$ref and $\Delta \mathrm{y} \_$ref shown in the Figure 8 using the parametric equation of the ellipse, on these images. These distances can be scaled from pixels to millimetres, knowing the radius of the shaft tip (R):

$$
\text { Scale_X }[\mathrm{mm} / \mathrm{pix}]=\frac{\mathrm{R}[\mathrm{mm}]}{\Delta \mathrm{x} \_ \text {ref }[\mathrm{pix}]} \text { and Scale_Y }[\mathrm{mm} / \mathrm{pix}]=\frac{\mathrm{R}[\mathrm{mm}]}{\Delta \mathrm{y} \_r e f[\text { pix }]}
$$

This double scale permits to correct the possible errors, due to faults in the placement of the camera and the lack of coaxiality between the axis of the turbo and the camera. Knowing these scales, it can be obtained the distance in millimetres between the screws $\left(\Delta \mathrm{d} \_\right.$ref $\left.[\mathrm{mm}]\right)$ from their distance in pixels $(\Delta d$ _ref [pix]). This distance is the distance between the two fixed points and therefore should be always the same, although the shaft is in motion or there is a relative motion between the camera and the turbocharger due to engine vibrations. Finally, this distance $(\Delta \mathrm{d}$ _ref) and the positions of screws (xi_ref, yi_ref, xd_ref and yd_ref) and shaft centre (Xc and Yc) are the parameters to be used for the processing of all the photos of the experiment performed with the turbocharger for which these parameters where obtained, with the objective of determining the relative motion of the shaft. The reference point used in this work is determined by the position of a reference screw. This reference point is used to determine the position coordinates of the shaft center (Xc, Yc). Variations in the position of this point (Xc, Yc) is what determines the movement of the shaft. However, alternative reference points could be considered, such the central point of the ellipse of maximum eccentricity. 


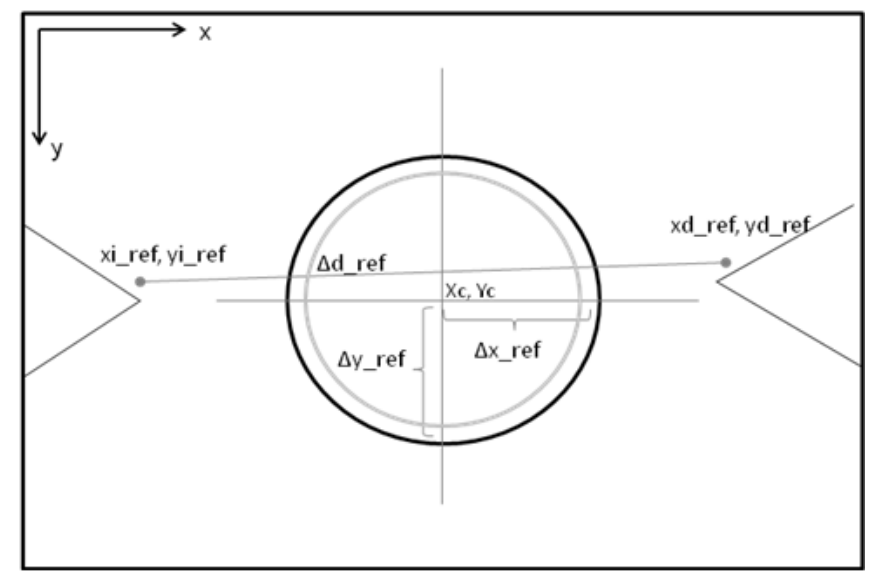

Figure 8 Scheme of shaft and screws

\subsection{Maximum eccentricity}

The maximum eccentricity is determined when the turbocharger is stopped, pressing radially the shaft from the turbine side in different directions (maximum eccentricity allowed by the components of the turbocompressor in order that it is kept in a normal functioning). After, these images with the shaft pressed are processed, in order to obtain each relative position of the shaft centre with respect to the positions of the reference screws. Processing of the images consists of locating the position in pixels of both screws and the centre of the shaft, as it has been described in the preceding paragraphs. Normally, the positions of the screws (xi_ref, yi_ref, xd_ref and yd_ref) in these pictures have changed with respect to the screws positions of the reference picture, this is due to possible relative movements between the camera and the turbocharger, they are normalized in order to become the fixed points of the experiment, since they are fixed to the compressor case and the important movement is that of the shaft centre with respect to them. Therefore, the relative position between both screws is used to determine the particular scale (scale $\mathrm{X}$ and it climbs $\mathrm{Y}$ ) of every image. These particular scales allow to relate the distance in millimeters and in pixels of each image. These scales are used to determine the position of both screws and the shaft centre in millimeters with respect to the fixed reference system determined by the screws.

Finally, the obtained shaft centre positions in millimetres relative to the screws position can be seen in Figure 9 with a correlated ellipse. This region of maximum eccentricity (ellipse) will be compared with the shaft motion when shaft is spinning. 


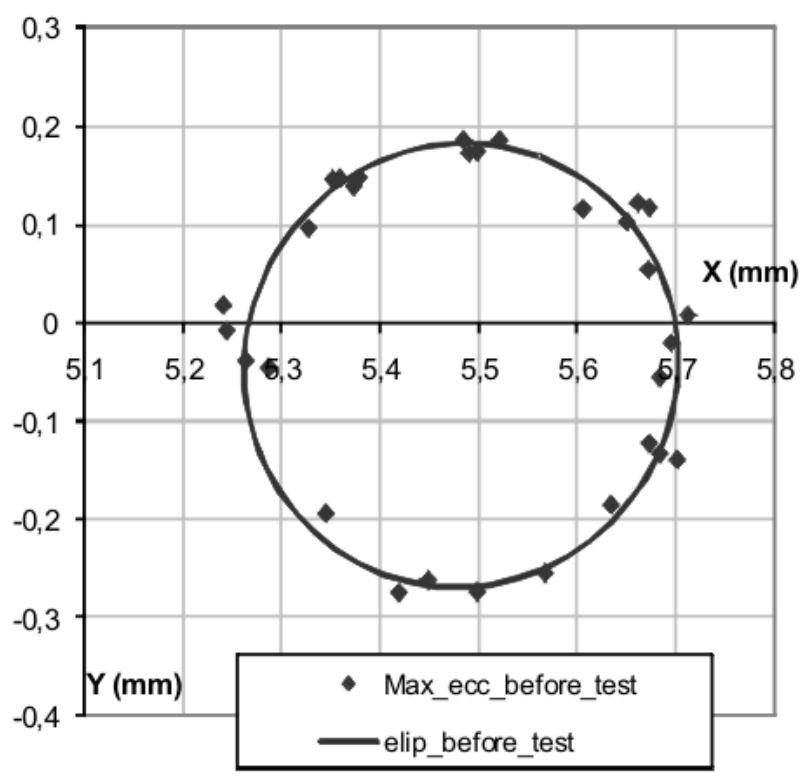

Figure 9 Maximum eccentricity points

\subsection{Shaft motion}

The next step, after the shaft maximum eccentricity has been processed, is to process the images with the shaft spinning. The image processing procedure is similar to the previous case; again the relative distance between the screws is used as a reference distance to determine the scale and shaft position when shaft is spinning. Figure 10 shows an example of this shaft motion. The big dots determine the maximum eccentricity and the small dots are the different positions of the shaft during a test at 150.000rpm and with an exposure time of $1 \mathrm{~ms}$.

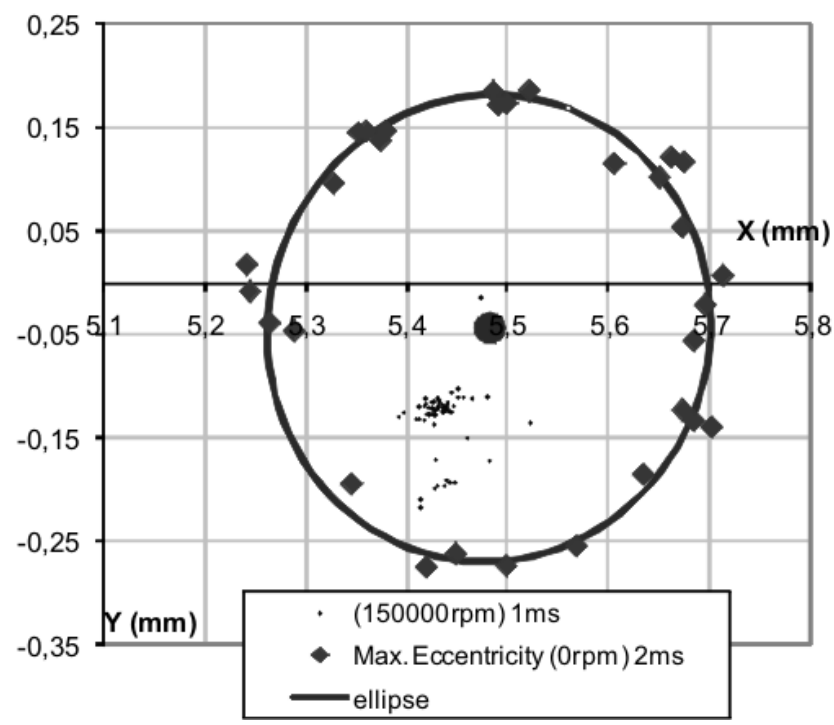

Figure 10 Maximum eccentricity and shaft motion points 
A parametric study was conducted in order to determine the optimal exposure time of the camera, for getting images. This study was done with the turbocharger spinning at 150000rpm and 60000rpm and with different camera's exposure times $(0.4,1,2$ and 4 $\mathrm{ms})$. The camera's exposure time was the parameter to optimize. The results are shown in Figure 11.

The results obtained indicate that if the exposure time of the camera is increased, the zone where the shaft is moving becomes more concentrated (Figure 11). This happens because the shaft spins and whirls more times within the time of a picture if the exposure time is increased. Consequently, all these whirls are captured in the obtained photograph. Thus, the theoretical centre of the shaft in the obtained picture is an average of the real shaft position during the exposure time that has been chosen.

On the other hand, greatly reducing the exposure time could cause that the zone where the shaft is moving cannot be processed with enough precision, because of poor image quality. This poor quality is due to a poor illumination of the shaft tip when the exposure time is too short and it causes that the obtained results, when the image is processed, do not have the necessary precision. So, the optimal result depends also on illumination power, in this study it was used a 250W lamp. If a higher power lamp is available, the exposure time could be reduced. Figure 11 shows that when the exposure time is too short, the final result can be illogical $(0.4 \mathrm{~ms})$, i.e. the axis is moving outside the logical limits set by the maximum eccentricity.

Summarizing, as it was remarked previously, the pictures with short exposure times do not capture enough light and consequently, saturation points in black prevent proper processing of the images. However, long exposure times can cause that the shaft has moved in many positions and consequently the information processing of the shaft motion does not transmit the exact position of the shaft, but a kind of average. Thus, the main purpose of this parametric study was that the camera works with exposure times as small as possible, without reducing the accuracy in calculations of shaft position. Thus, the optimal resolution in this parametric study was to work with an exposure time of $1 \mathrm{~ms}$ (Figure 11). During this period of 1ms, if the shaft is spinning at $150000 \mathrm{rpm}$, the shaft will be rotated 2.5 times. Such study to optimize the exposure time should be performed before any new turbocharger model would be tested with this proposed technique. If these results with exposure times of $1 \mathrm{~ms}$ are compared, it can be observed that the position in which the shaft is moving changes depending on the engine speed. The smaller the engine speed, the greater is the variation of the eccentricity of the shaft movement (the zone in which the shaft is moving is larger). These results are consistent with theoretical lubrication models for bearings. 
$60000 \mathrm{rpm}$
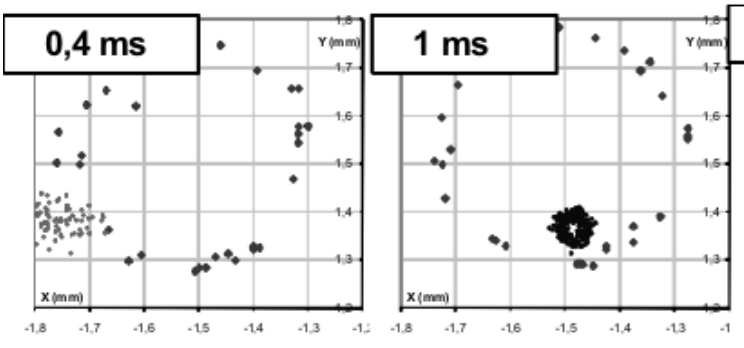

Exposuretime 1ms
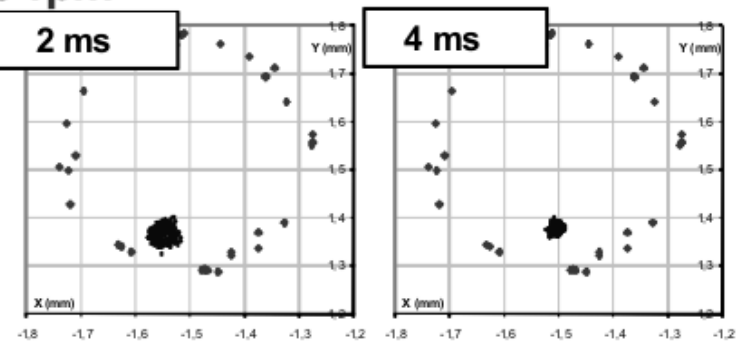

Exposure time $0,4 \mathrm{~ms}$

Exposure time $2 \mathrm{~ms}$

Exposure time $4 \mathrm{~ms}$

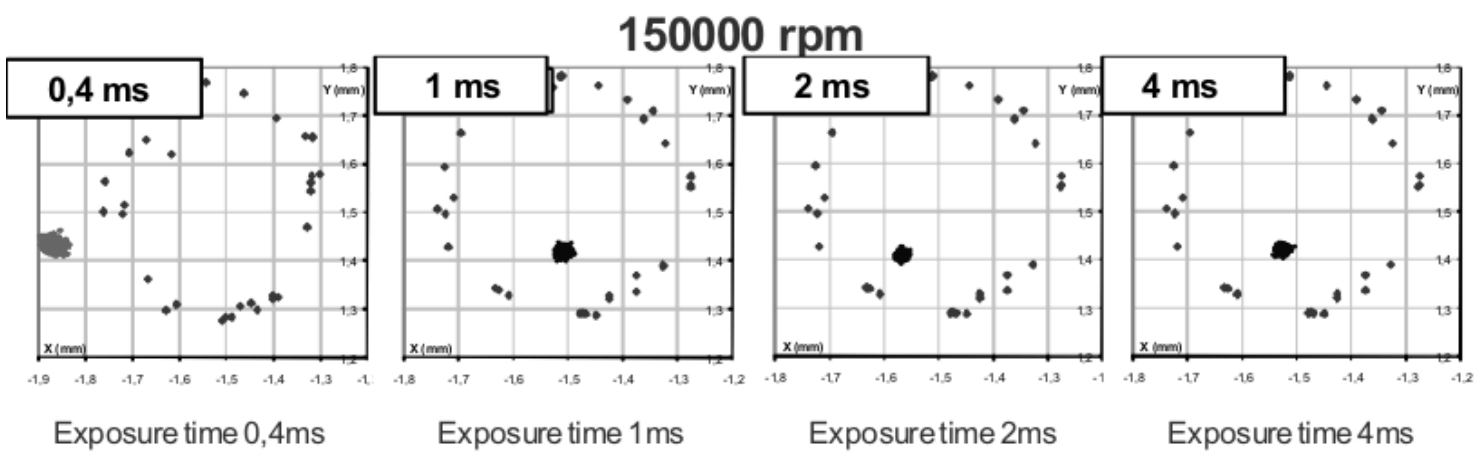

Figure 11 Shaft motion (exposure time study)

\subsection{Luminosity analysis}

A preliminary study about the shaft illumination must be done, before the shaft motion study. The study consists of observing the image quality of photos with different exposure times. As it was remarked previously, the pictures with short exposure times do not capture enough light and saturation points in black prevent proper processing of the images. However, long exposure times can cause that the shaft had moved through many positions and consequently the information processing of the shaft motion does not transmit the exact position of the centre, but a kind of average.

An analysis of the radial light gradients and patterns, between a processed picture and a reference picture, may be used to determine the relative displacement during the exposure time between this processed photography and the reference; i.e. during the 2.5 turns at $150 \mathrm{krpm}$ claimed in previous section. It is necessary to follow several steps to perform the analysis of the radial brightness at a certain radial angle $(\alpha)$ :

1. To get the lighting pattern for the studied radial shaft angle ( $\alpha)$. This pattern is obtained from a grey scaled reference picture. This reference picture is a photo taken where the shaft is moving in its "normal" operation, it means stable and lubricated by oil. It is considered the reference movement. This picture should have a very small "halo" around the shaft tip. Figure 12 a) shows a sketch of this radial luminosity pattern on a radial angle $(\alpha)$ with a 
shaft tip of ring shape (Figure 13). A point to consider is that the radial luminosity gradient in the metallic surface of the shaft tip depends on the angle observed. A radial angle of the shaft tip can receive more light than other due to the direction of the light to the turbocharger shaft tip.

2. To compare the reference pattern obtained in the previous step with the processed photo for a studied angle $(\boldsymbol{\alpha})$. If the turbocharger is tested with different conditions than the reference condition, i.e. with abnormal lubrication, the shaft could be moving with a different pattern when the photo is taken. When this photo is processed it will have a different "halo" around the shaft tip, due to the whirl motion of the shaft during the exposure time of the picture. Figure $12 \mathrm{~b}$ ).

3. To determine the shaft shape differences (halo difference between the reference and the processed photo). This halo difference is related with the distance that the shaft has moved during the exposure time of the photo. It is because the halo represents the zones where the shaft has been present during this exposure time. Then, an increment in the halo represents higher displacements of the shaft during the exposure time. Thus, comparing the difference between the reference radial pattern and the processed radial pattern of their halos, it is possible estimate the shaft displacement as Figure 12 c) shows.

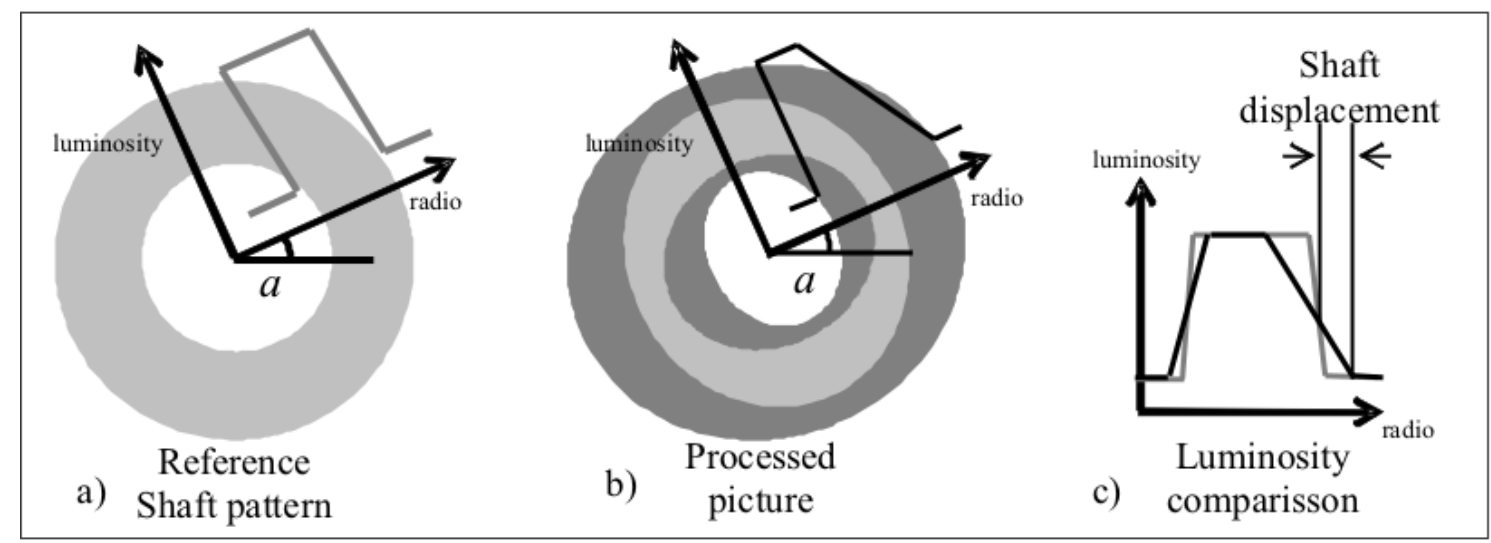

Figure 12 Luminosity comparison process

Several images obtained during the test with abnormal lubrication conditions (no-oil pressure) showed sudden movements of the shaft during their exposure time. In order to illustrate this technique, two of these photographs were processed by the luminosity analysis technique described previously. The Figure 13 a) photograph was taken in the second 57th and the Figure $13 \mathrm{~b}$ ) photograph was taken in the second 274th of the test. Figure 13 shows these images. 
The shaft motion was studied in different radial directions $\left(0^{\circ}, 45^{\circ}\right.$ and $\left.90^{\circ}\right)$ by means of the luminosity analysis. Figure 13 Reference shows these directions on the reference picture of the shaft tip.

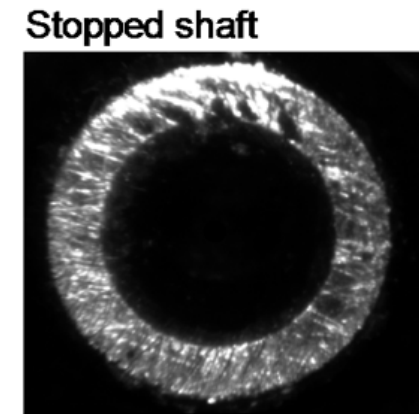

a)

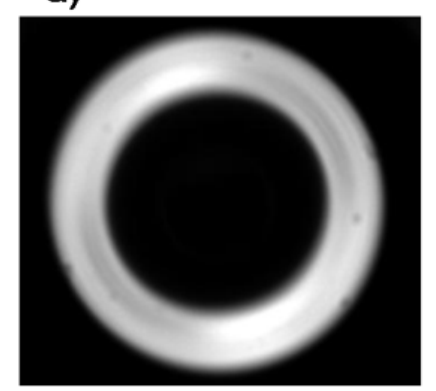

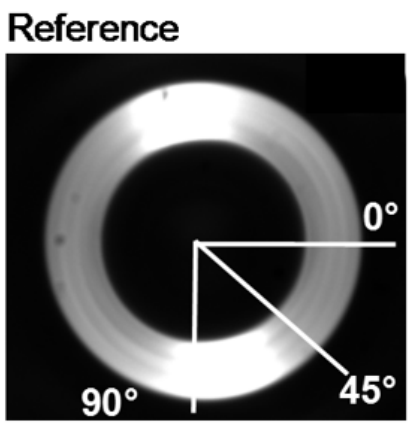

b)

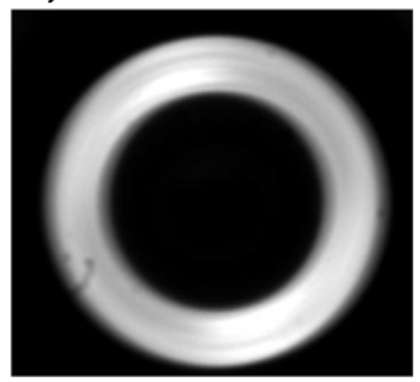

Figure 13 Studied angles on the reference picture and processed pictures

As an example, Figure 14 shows the luminosity analysis of these studied images for the $0^{\circ}$ angle. The relative displacement of the shaft during the exposure time of the photograph is obtained from these graphs. To analyze this luminosity, the grey colors of the image in the studied angle have been scaled using 0 with the darkest pixel and 1 with the brightest one. Figure 14 shows this scaled luminosity versus radial position in microns. This plot shows that the most luminous area is located between the 1000 microns and the 1750 microns (the shaft has a radius of 1750 microns). The shape of this area depends on the reflections of the light on the shaft tip. The slope of the two light gradients located from 1000 to 1250 microns and from 1500 to 1750 microns, depends on the radial movement of the shaft in the studied direction during the exposure time of the photography. To estimate this radial movement, the variation of the slope inclination is evaluated at a reference point placed at 0.1 non-dimensional luminosity, as can be observed in Figure 14. 


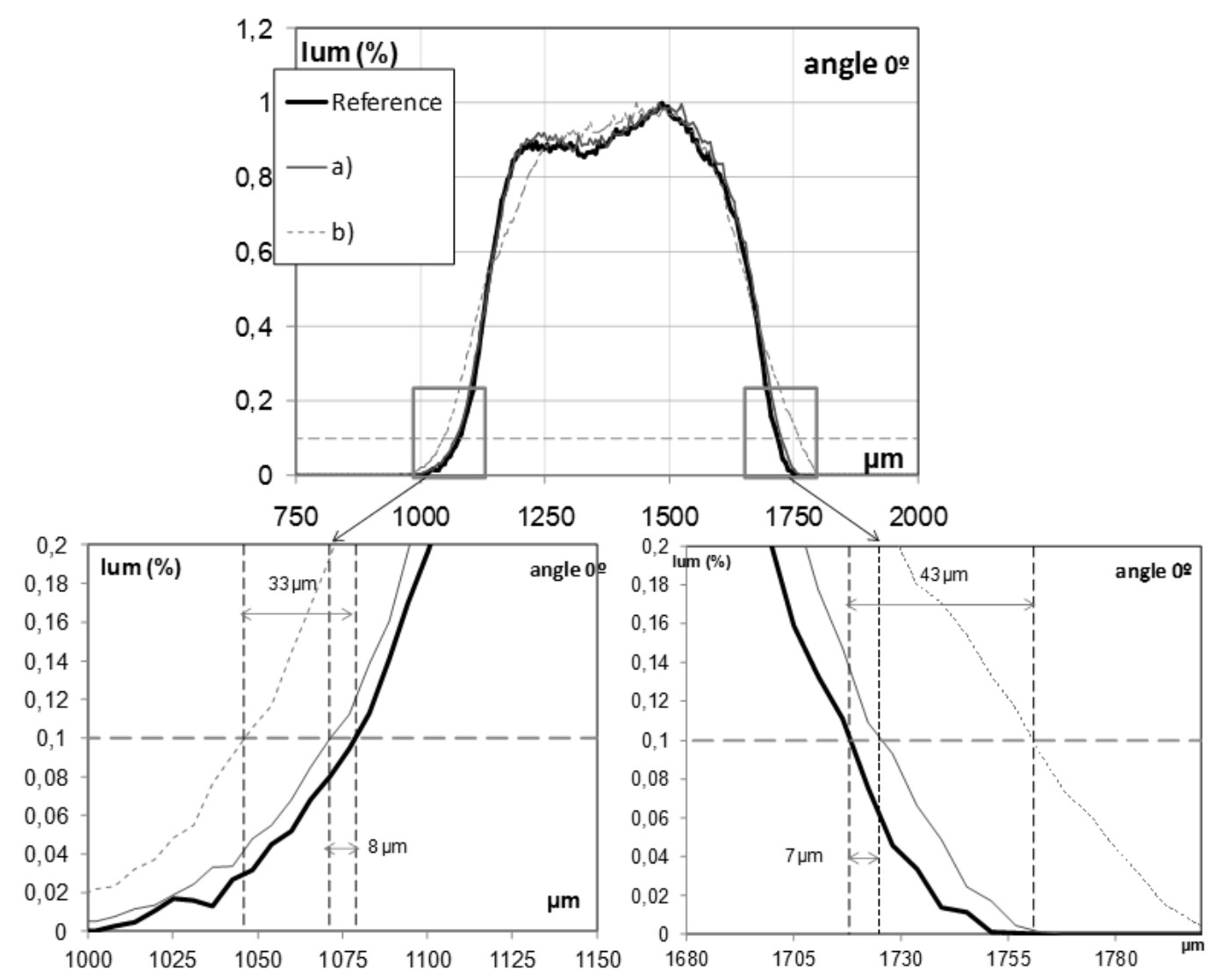

Figure 14. Luminosity analysis for $0^{\circ}$ direction

Figure 15 shows the spatial representation of the estimated positions of the shaft for each of the photographs taken during the test. The two pictures shown in Figure 13 a) and in Figure $13 \mathrm{~b}$ ) are those in which it has been detected a greater movement of the shaft during the exposure time of the respective photographs. Figure 15 shows the relative movement of these two points on the studied directions $\left(0^{\circ}, 45^{\circ}\right.$ and $\left.90^{\circ}\right)$. Figure 15 shows that this relative movement of the shaft in some cases becomes approximately $80 \mu \mathrm{m}$ during the exposure time of photography. It is a sharp movement during the short period of the photograph exposure time as (2.5 turns) can be observed in the segments drawn in the two studied points at Figure 15. 


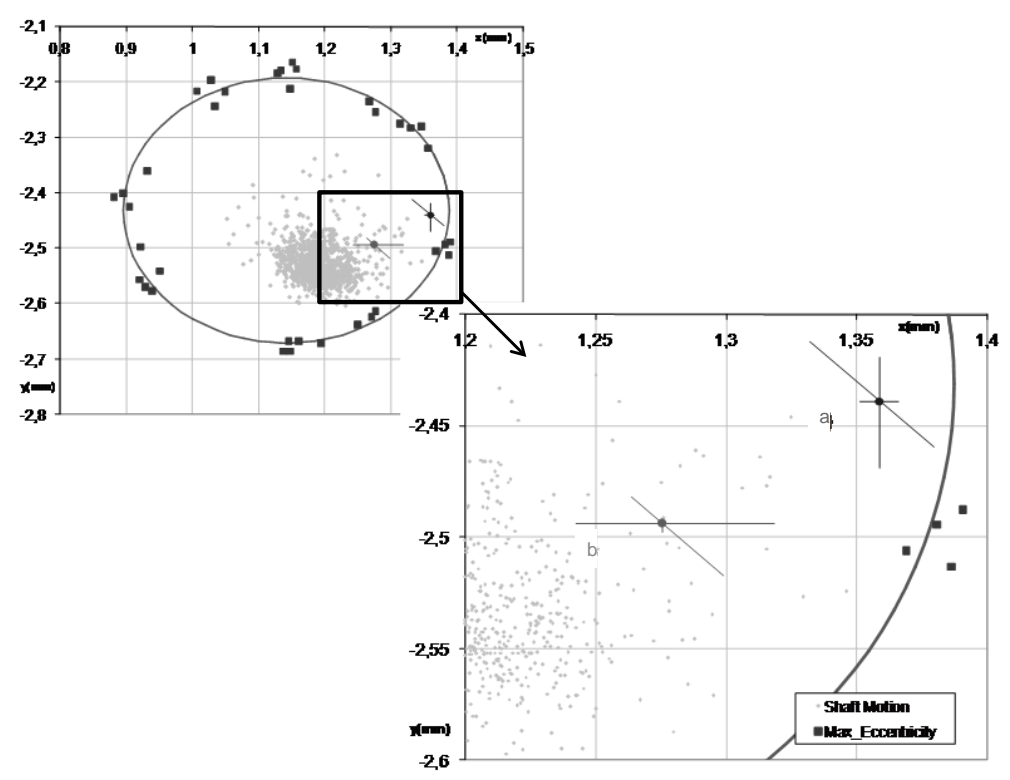

Figure 15. Shaft motion

\section{APPLICATION OF THE METHODOLOGY AND DISCUSSION OF THE RESULTS}

The methodology described above was used to get information about the turbocharger shaft motion during a lubrication failure test. This test consists on stabilizing the turbo with specific parameters (oil inlet pressure 2 bar, turbine inlet pressure 1.85 bar, compressor outlet pressure $1.7 \mathrm{bar}$ and turbocharger spinning at $150000 \mathrm{rpm}$ ) and suddenly, the lubrication oil flow is cut until the turbocharger suffers a severe failure. Figure 16 shows the main thermodynamic variables during the test. Figure 16 shows that the lubrication was cut at second 39th, then, the turbine inlet pressure remains constant (consider that this experiment has been performed in the test bench sketched in figure 1) and the compressor outlet pressure decreases almost linearly to 1.6 bars during 5 seconds. Suddenly, the turbocharger shaft hits with the housing and a big failure takes place, the shaft begins to move in an erratic displacement and the wheel continues kicking and scratching with the housing. This erratic movement produces an increment in the gas temperature at turbine outlet due the erratic movement comes a lost of efficiency also in the turbine and the compression capacity is lost boost pressure drops to 1 in the compressor side. 


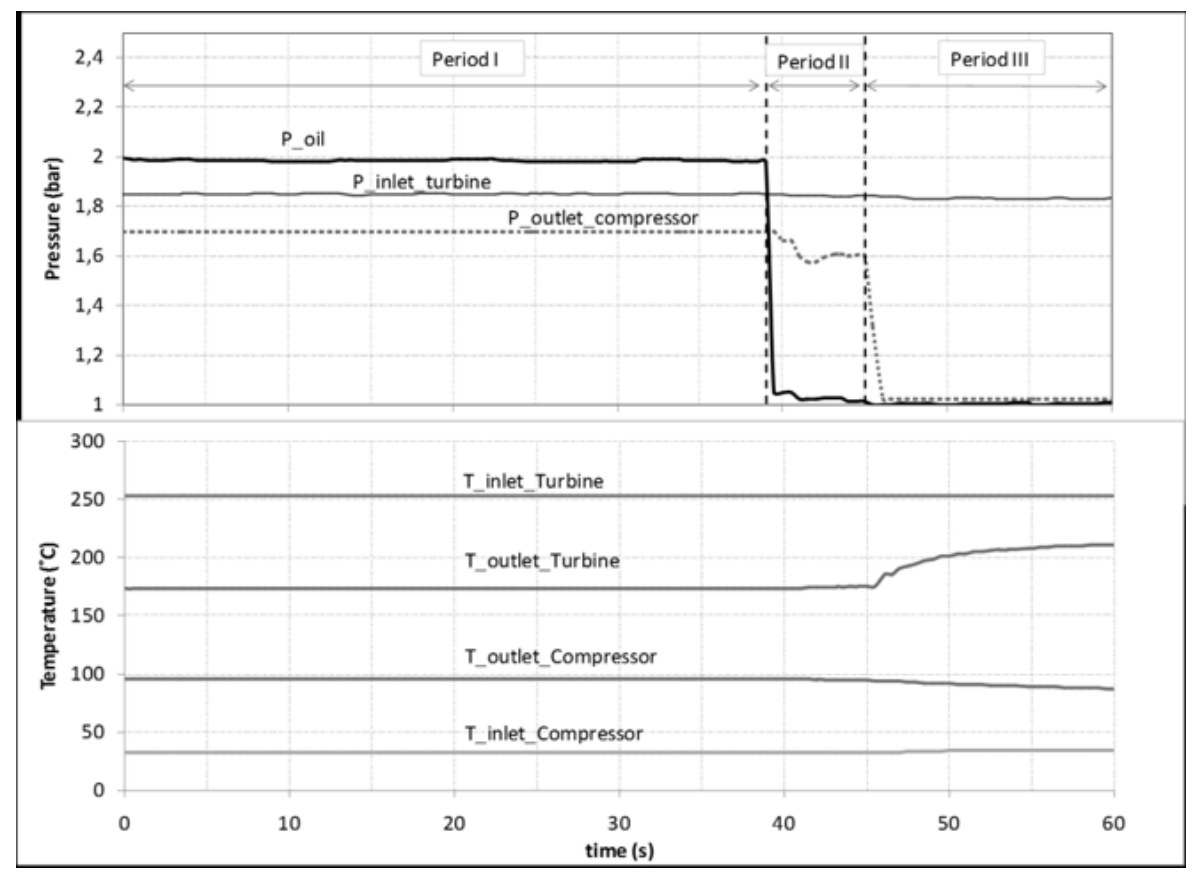

Figure 16 Pressures in turbocharger test

Figure 17 shows different graphs with the shaft motion analysis, dividing the test into four periods. In addition, this figure also shows a typical picture of each of these periods:

- "Period I" is the stage from the beginning until about second 39th of the test. During this stage the turbocharger works properly lubricated with oil pressure at 1.98 bar (Figure 17 left side). This graph shows that the movement of the shaft is in "Zone I".

- "Period II" is the stage from second 39th until second 45th. This stage starts when the oil pressure is cut. After, the compressor outlet pressure begins to decrease and the shaft shows a sharp movement over the limits of maximum eccentricity. This period finishes when the compressor blades hit the housing and they are deformed, causing the destruction of the turbocharger. During this stage, the shaft is located in "Zone II". The higher halo (like a lost of focus) in the pictures is a clear sign of the higher shaft motion and of picture to picture dispersion.

- Finally, "period III" is the stage from the 45th second to the end. At this stage, the shaft is moving erratically and the turbocharger efficiency is zero. This produces a total lost of the compression work. Figure 17 right side shows a typical picture of this erratic movement. This erratic movement implies that the compressor wheel is knocking repeatedly the compressor housing, producing erratic and sharps movements of the shaft. An increment of the turbine outlet temperature can be observed, due to this malfunction. During this period, it is 
not possible to process the images, due to sharp and not homogeneous movement implies a distorted image of the shaft tip.

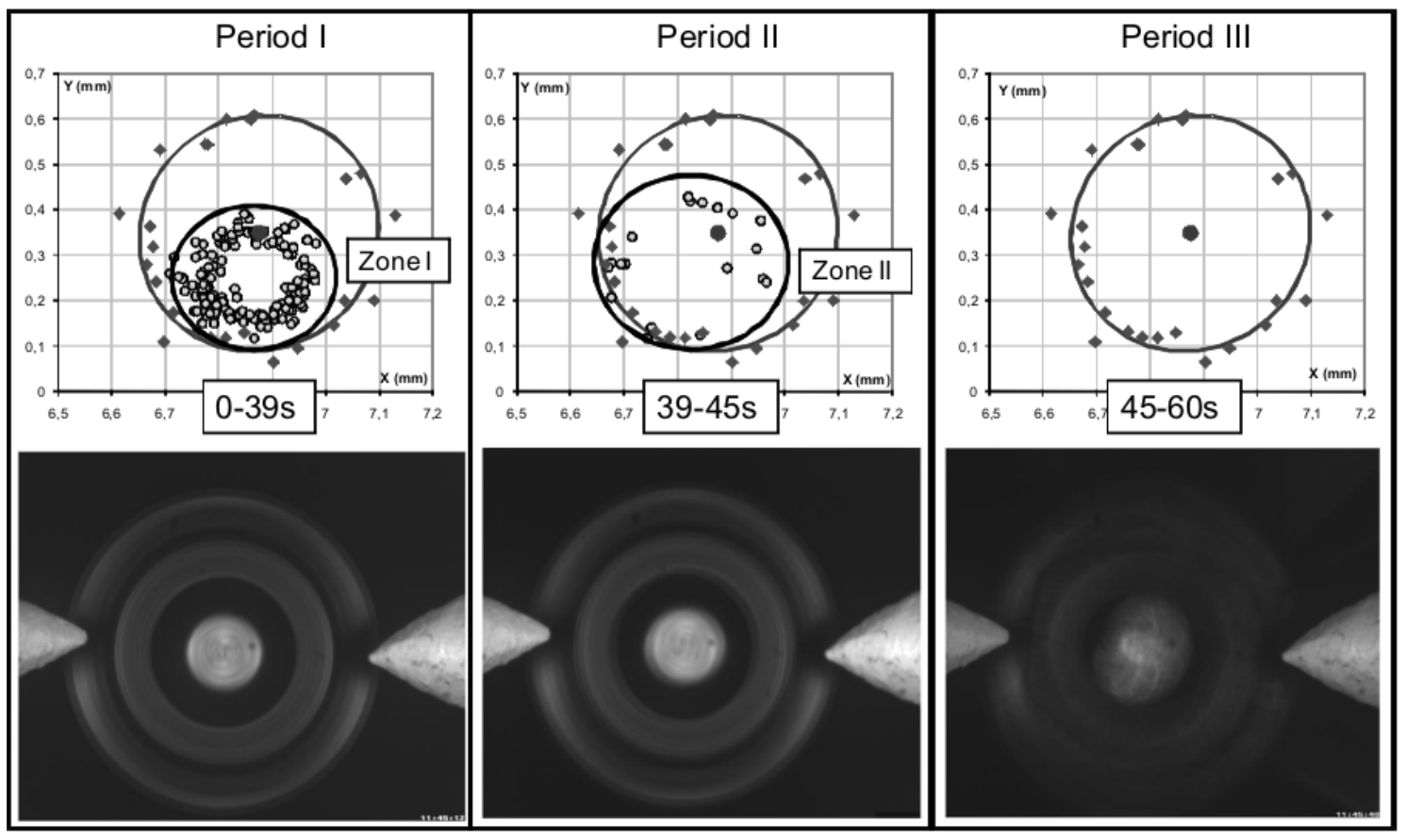

Figure 17 Shaft motion during the lubrication failure test

Figure 18 shows the sequence of the turbocharger severe failure appearance. The first picture of the sequence ("11:45:41") is the last photo with the turbo properly lubricated. The diameter of the shaft at the compressor tip is indicated in this first picture. Thereafter, the oil is cut and, as noted above, the turbo is destroyed a few seconds later. The first picture with the turbocharger broken is the labeled photograph "11:45:47". When the shaft is destroyed, the movement of the shaft becomes as an erratic motion (the last three pictures of the sequence). This erratic movement is produced because the shaft exceeds the maximum eccentricity area and consequently, the compressor blades hit and scratch the compressor housing. The last picture shows the movement magnitudes of the shaft tip, during this last phase with the erratic movement. The picture shows that the shaft is hitting and rebounding with displacements of $1 \mathrm{~mm}$ in all radial directions during the exposure time of the photograph (1ms). 

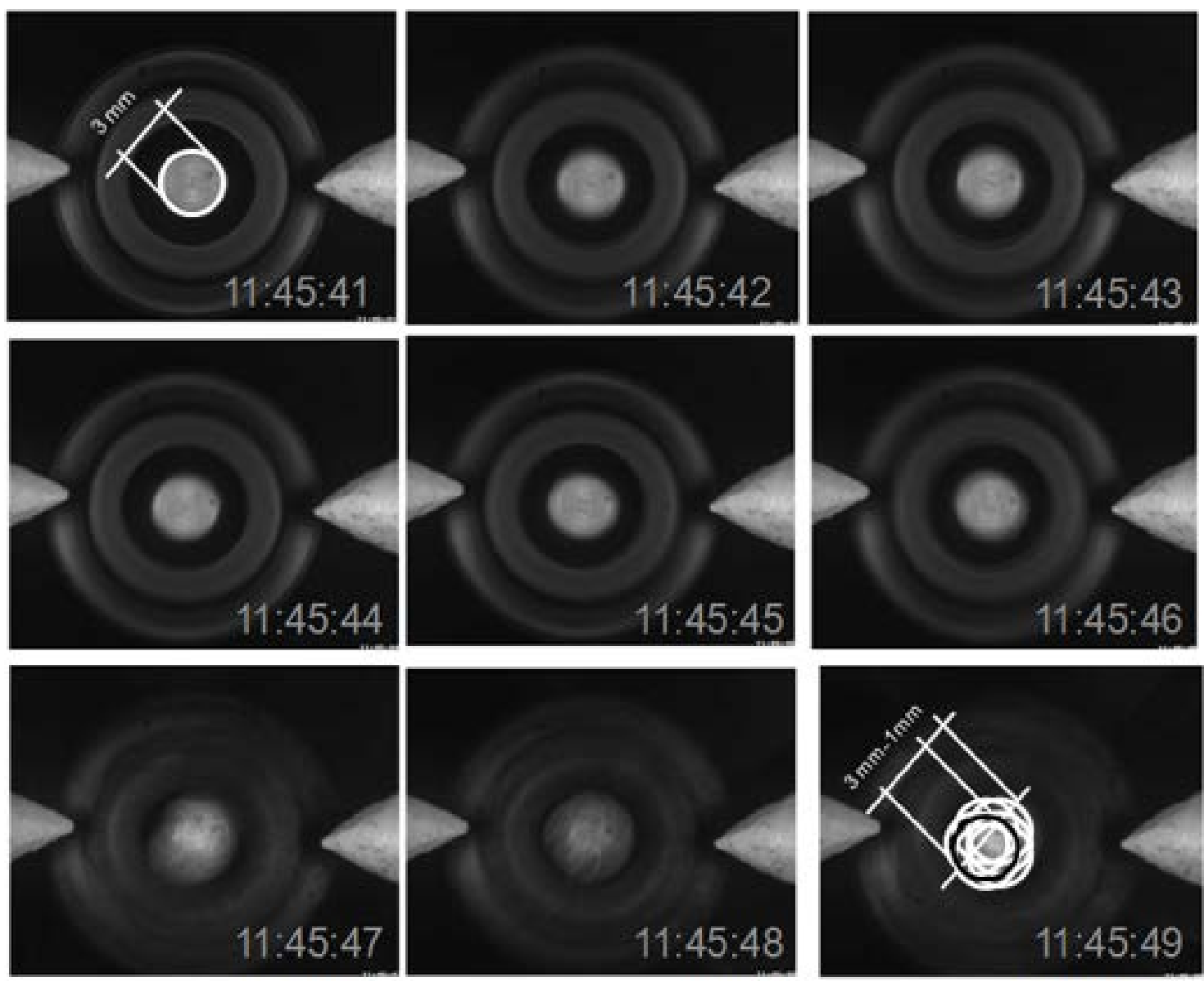

Figure 18 Destruction Sequence

Figure 19 shows the main damage in the compressor blades and in the shaft, after the described lubrication failure test, corresponding to the results represented in the Figure 16 and Figure 17. Figure 19 a) shows the deformation and milling of compressor blades due to the knocks and the scrapes against the compressor housing. This malfunction causes a temperature rise in the bearings due to friction between the shaft and the bearing. So, it produces temper colors in the shaft and addition of radial bearing material into the shaft, as can be observed in Figure 19 b).

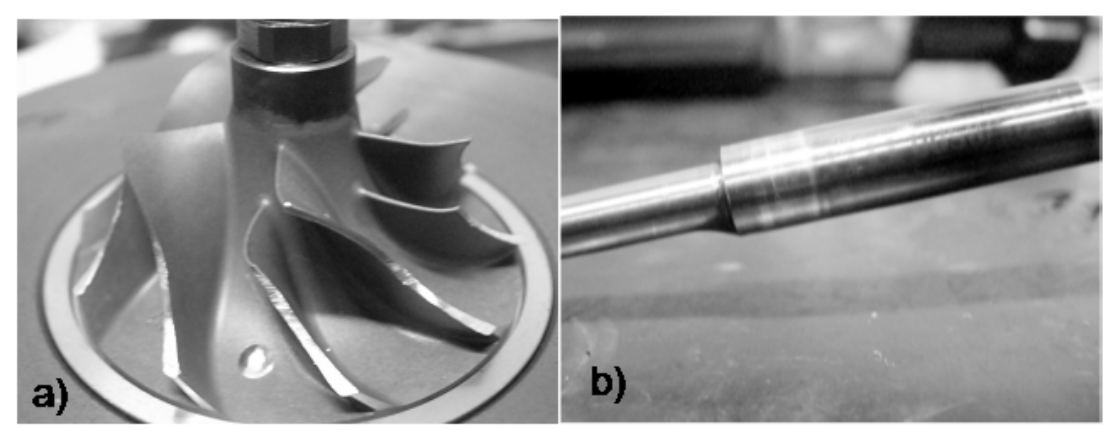

Figure 19 Compressor wheel and shaft after the test. 


\section{CONCLUSIONS}

This article describes a methodology to observe the whirl of a turbocharger shaft when it is spinning. This technique is simple and relatively easy to implement in a test bench room, because it is not excessively intrusive. Other measurement techniques used, like accelerometers, laser techniques or displacement sensors are also able to estimate the movement of the shaft. However, laser techniques and displacement sensors are very intrusive techniques compared with this optical technique, which has a wide field of improvement through the use of higher quality cameras and light sources with more power. In addition, the technique described, as it is a photographic technique, allows extracting visual information from the test, like the appearance of oil on the compressor side, sudden movements of the shaft or possible deformations of the area focused by the camera. Another highlight in the proposed methodology is that the measuring elements can resist any destructive failure of the turbocharger, because the camera is out of the turbocharger, and the reference screws, which are placed in the turbocharger, are easily replaceable.

The accuracy obtained with the camera and with the light source used in this work is $5 \mu \mathrm{m}$ per pixel during an exposure time of $1 \mathrm{~ms}$. This accuracy allows observing with enough precision the movement of the shaft on the side of the compressor when it is spinning. Although, this information is not enough to determine the three-dimensional position of the shaft at every time instant, whether it provides important information when the photographed shaft position is compared with the maximum eccentricity zone permitted by the turbocharger bearings system. Thus, when the shaft is closest to the maximum eccentricity zone, the possibilities of the turbocharger to suffer a critical damage increases.

Finally, this type of technique has been used to observe the movement of the shaft in a test in which the turbo lubrication is cut until it breaks. The operation of the turbochargers used in internal combustion engines, when their lubrication systems have typical problems is an issue of great interest, due to the increased demands on turbochargers and on their lubrication systems. In the test shown as an example in this article, the different patterns of movement of the shaft can be observed, when the lubrication is cut. The graphs obtained from the test show the increase in eccentricity of the shaft when the turbocharger oil flow is cut. At the end of the test, few seconds before the critical failure, a sudden movement of the shaft causes it to be positioned outside the limits set by the maximum eccentricity, causing the critical failure of the turbo. After, the turbocharger efficiency decreases and practically all the energy supplied by the turbine is consumed by the bumps and scratches of compressor and turbine blades and the different parts of the shaft bearings. Moreover, as noted earlier, this technique allows observing the presence of oil in the compressor side where, due to abnormal functioning of the turbo, the oil can passes from the lubrication circuit to the compressor inlet, because of the pressure difference. 


\section{REFERENCES}

[1] Jeffcott H.H. The Lateral Vibration Loaded Shafts in the Neighborhood of a Whirling Speed. The Effect of Want of Balance. Philosophical Magazine 1919; 637.

[2] Nelson F.C. Rotor Dynamics without Equations. International Journal of COMADEM 2007; 10(3): 2-10.

[3] Tian L., Wang W.J. and Peng Z.J. Dynamics behaviours of a full floating bearing supported turbocharger rotor with engine excitation. Journal of Sound and Vibration 330; 2011: 48514874 .

[4] Flores P., Pimenta Claro J.C. and Ambrósio J. Journal Bearings Subjected to dynamic loads: The analytical mobility Method. Revista da Associaçäo Portuguesa de Análise Experimental de Tensöes ISN -122 922.

[5] Green I. and Casey C. Crack Detection in a Rotor Dynamic System by Vibration Monitoring -Part I: Analysis. Journal of Engineering for Gas Turbines and Power 2005; 127: 425-436.

[6] Schweizer B. Dynamics and stability of turbocharger rotors. Arch Appl Mech 2010; 80: 10171043.

[7] Günther P., Dreier F., Pfister T., Czarske J., Haupt T. and Hufenbach W. Measurement of radial expansion and tumbling motion of a high-speed rotor using an optical sensor system. Mechanical Systems and Signal Processing 2010; 25: 319-330.

[8] Podevin P., Clenci A. and Descombes G. Influence of the lubricating oil pressure and temperature on the performance at low speeds of a centrifugal compressor for an automotive engine. Applied Thermal Engineering 2011; 31: 194-201.

[9] Deligant M., Podevin P. and Descombes G. CFD model for turbocharger journal bearing performances. Applied Thermal Engineering 2011; 31: 811-819.

[10] Gertzos K.P., Nikolakopoulos P.G., Chasalevris A.C., Papadopoulos C.A. Wear identification in rotor-bearing systems by measurements of dynamic bearing characteristics. Computers and Structures. 89 (2011) 55-56.

[11] Serrano J.R., Tormos B., Gargar K.L. and Bouffaud F. Study of the effects on turbocharger performance generated by the presence of foreign objects at the compressor intake. Experimental Techniques (2011) Society for experimental Mechanics.

[12] Galindo J., Serrano J.R., Guardiola C. and Cervelló C. Surge limit definition in a specific test bench for the characterization of automotive turbochargers. Experimental Thermal and Fluid Science. 2006;30: 449-462.

[13] Chauvin J., Moulin P., Corde G., Petit N. and Rouchon P. Real-Time nonlinear individual cylinder air fuel ratio observer on a Diesel engine test bench. In Proc. of the IFAC World Congress, 2005. 
[14] Payri F., Galindo J., Climent H. and Guardiola C. Measurement of the oil consumption of an automotive turbocharger. Experimental Techniques. September/October 2005. 